\title{
Pressure Ulcer Incidence and Blood Lactate Levels in Intensive Care Unit Patients
}

\author{
Anna Woźniak', Irena Smółka ${ }^{2}$, Aleksandra Dusińska $\mathbb{D}^{3}$, Weronika Misiąg $\mathbb{D}^{3}$, Mariusz Chabowski $\mathbb{D}^{4,5}$ \\ 'Department of Anaesthesiology and Intensive Care, 4th Military Teaching Hospital, Wroclaw, Poland; ${ }^{2}$ Department of Anaesthesiology and Intensive \\ Therapy, Wroclaw Medical University, Wroclaw, Poland; ${ }^{3}$ Student Research Group No. I80, Faculty of Medicine, Wroclaw Medical University, \\ Wroclaw, Poland; ${ }^{4}$ Department of Nursing and Obstetrics, Faculty of Health Science, Wroclaw Medical University, Wroclaw, Poland; ${ }^{5}$ Department of \\ Surgery, 4th Military Teaching Hospital, Wroclaw, Poland \\ Correspondence: Mariusz Chabowski, Tel +48 26I 660 247, Fax +48 26 I 660 245, Email mariusz.chabowski@gmail.com
}

\begin{abstract}
Introduction: Pressure ulcers are an important indicator of hospital care quality and a costly complication of intensive care. The incidence of PU is influenced by individual patient factors and the type of treatment used. Patients after surgery have been shown to have reduced albumin levels and elevated blood lactate levels. Increased lactate levels are associated with tissue hypoxia, increased morbidity and mortality.

Aim: The aim of the study was to establish the relationship between the incidence of pressure ulcers and blood lactate levels in intensive care unit patients.

Material and Methods: Our retrospective and non-randomized study was conducted among 125 patients treated at the Department of Anesthesiology of the 4th Military Teaching Hospital in Wroclaw between 2019 and 2020. The inclusion criteria were as follows: the use of intubation, analgosedation and vasopressors during intensive care treatment. The patients were divided into three main groups, which were each divided into two subgroups differing in blood lactate levels. We analyzed the patients' lactate levels, as measured by arterial blood gas analysis, and monitored their pressure ulcers using their medical records: the pressure ulcer monitoring chart, the Waterlow pressure ulcer risk assessment chart, history of present illness and medical history.

Results: Lactate levels in the patients studied ranged between 0.2 and $30.0 \mathrm{mmol} / 1$. The incidence of pressure ulcers in ICU patients is $8.8 \%$.

Conclusion: The incidence of pressure ulcers in ICU patients is not different from the incidence rates reported in the literature. The study did not show a correlation between the patients' arterial blood lactate levels and the incidence of pressure ulcers. Considering the low expected values due to the small number of patients in each subgroup, the findings should be treated with caution. Given the importance of pressure ulcers, a larger population study covering a longer period of time seems warranted.
\end{abstract}

Keywords: pressure ulcers, lactate levels, intensive care unit, tissue hypoxia

\section{Introduction}

Pressure ulcers are an important indicator of hospital care quality ${ }^{1}$ and a costly complication of intensive care. ${ }^{2}$ Despite numerous studies on the causes of PU development, PU remain a major problem in hospital settings. ${ }^{3}$ According to a 2017 report by NPUAP, each year 2.5 million patients in the US develop PU and 60,000 die from their complications as a result of inadequate treatment. A review of epidemiological studies comparing the prevalence and incidence of PU in Europe, USA and Canada found that the reported prevalence of PU in European hospitals ranged between 8.3\% and $23 \%$. ${ }^{4}$ In the UK, the prevalence of PU in care settings was estimated at $10.2 \%$, whereas the prevalence of PU in the USA and Canada ranged between $12.3 \%$ and $33 \% .{ }^{5,6}$ It is estimated that in Poland PU affect over 500,000 patients. According to a study on the prevalence of PU in Europe, it is estimated that one in four patients in neurology wards and one in five intensive care unit patients will develop PU. ${ }^{7} \mathrm{PU}$ are a global issue and a burden to patients and the healthcare system. The development of pressure ulcers in hospital settings is associated with increased length of hospital stay and increased treatment costs. According to a report by the Centres for Medicare \& Medicaid Services, the 
costs associated with treating hospital-acquired PU in US patients amount to USD 146 million a year. ${ }^{8}$ The identification and analysis of as many causes of the condition as possible would improve treatment effectiveness and reduce healthcare costs. There are significant differences in the prevalence of hospital-acquired pressure ulcers between intensive care units and other types of wards. This reflects the impact of critical illness on pressure ulcer development. ${ }^{9}$ Intensive care treatment involves the use of respirators, urinary catheters and multiple intravenous catheters as well as the use of analgesics, muscle relaxants and sedatives, which cause a reduction in sensory perception, leading to a reduced reaction to pressure. ${ }^{10}$ They may create additional health complications for the patient. ${ }^{11}$ Pressure ulcers can be a source of infection and have a negative impact on the patient's mental and physical health. ${ }^{12}$ Hospital-acquired pressure ulcers may contribute to increased mortality. Low pressure ulcer prevalence is a marker of good quality of health care. ${ }^{9}$ The incidence of PU is influenced by individual patient factors and the type of treatment used. ${ }^{6}$ Numerous risk factors for PU have been identified in current research, including critical illness, older age, prolonged length of hospital stay, immobility, tissue hypoperfusion, poor nutrition, poor skin condition, being female as well as obesity. ${ }^{13-18}$ Scientific publications have confirmed that there is an association between increased pressure ulcer risk and endogenous factors such as anaemia, decreased albumin levels, MAP $<60-70 \mathrm{mmHg}$, diabetes, and the age of the patient. ${ }^{10,19-22}$ Intraoperative and perioperative factors that have been found to be associated with pressure ulcer development include anaesthesia, duration of surgery, surgical position, and the postoperative bed used. ${ }^{23-25}$ There are also studies that have found that the use of blood products during surgery is associated with the development of postoperative pressure ulcers. ${ }^{26}$ Other external risk factors for pressure ulcer development include the duration of stay in the hospital, mechanical ventilation, hemofiltration, haemodialysis and the use of vasopressors. ${ }^{2,10,27,28}$

Patients after surgery have been shown to have reduced albumin levels and elevated blood lactate levels. ${ }^{29}$ Lactate levels may be increased in many pathological conditions. The monitoring of lactate levels allows for the detection of an existing or imminent critical illness. Lactate is a product of anaerobic glycolysis that may cause severe metabolic disturbances. Increased lactate levels are associated with tissue hypoxia as well as increased morbidity and mortality. ${ }^{30-32}$

So far the impact of blood lactate levels on the development of pressure ulcers in intensive care unit patients has not been investigated.

The aim of the study was to establish the relationship between the incidence of pressure ulcers and blood lactate levels in intensive care unit patients.

\section{Materials and Methods}

The study was conducted among 125 patients (77 men and 48 women) treated at the Department of Anaesthesiology of the 4th Military Teaching Hospital in Wroclaw between October 2019 and March 2020. The patients included in the study were both patients after surgery and with internal diseases. The patients were divided into three main groups, which were each divided into two subgroups differing in blood lactate levels (subgroup A - patients with lactate levels within the normal range, subgroup B - patients with lactate levels above the reference range).

The first group included patients with no pressure ulcers on admission and at discharge. The second group included patients who had no pressure ulcers on admission but had pressure ulcers at discharge. The last group included patients with pressure ulcers on admission and at discharge. Lactate levels were measured by arterial blood gas analysis in each of the patients studied at least several times, with the minimum and maximum lactate levels in each patient being used for analysis (Figure 1).

The criteria for inclusion in group one were as follows: the use of intubation, analgosedation and vasopressors, duration of stay in ICU of at least 48 hours, absence of pressure ulcers on admission and at discharge. The criteria for inclusion in group two were as follows: the use of intubation, analgosedation and vasopressors, duration of stay in ICU of at least 24 hours, pressure ulcers acquired during the patient's stay in ICU. The criteria for inclusion in group three were as follows: duration of stay in ICU of at least 48 hours, presence of pressure ulcers on admission and the use of the treatment listed in criteria for inclusion in groups one and two. 


\section{Study flow}

\begin{tabular}{|c|c|c|c|}
\hline : & $\begin{array}{l}\text { Patients treated at the } \\
\text { Department of Anesthesiology } \\
\text { of the } 4^{\text {th }} \text { Military Teaching } \\
\text { Hospital in Wroclaw between } \\
10.2019 \text { and } 03.2020 \\
(n=125)\end{array}$ & \multicolumn{2}{|c|}{$\begin{array}{l}\text { Patients admitted to ICU due to a life-threatening condition. } \\
\text { The patients included in the study were patients after surgery and with } \\
\text { internal diseases. }\end{array}$} \\
\hline \multirow{4}{*}{ 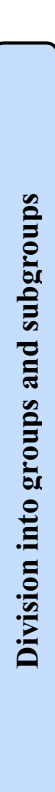 } & & Min. Lactate levels & Max. Lactate levels \\
\hline & $\begin{array}{l}\text { Absence of pressure ulcers at } \\
\text { any time }\end{array}$ & $\begin{array}{l}\text { Subgroup A: lactate levels within } \\
\text { the normal range }(\mathrm{n}=69) \\
\text { Subgroup B: lactate levels above the } \\
\text { normal range }(>1.6 \mathrm{mmol} / \mathrm{l})(\mathrm{n}=10)\end{array}$ & $\begin{array}{l}\text { Subgroup A: lactate levels within } \\
\text { the normal range }(\mathrm{n}=34) \\
\text { Subgroup B: lactate levels above the } \\
\text { normal range }(>1.6 \mathrm{mmol} / \mathrm{l})(\mathrm{n}=52)\end{array}$ \\
\hline & $\begin{array}{l}\text { Pressure ulcers acquired during } \\
\text { ICU stay }\end{array}$ & $\begin{array}{l}\text { Subgroup A: lactate levels within } \\
\text { the normal range }(\mathrm{n}=11) \\
\text { Subgroup B: lactate levels above the } \\
\text { normal range }(>1.6 \mathrm{mmol} / \mathrm{l})(\mathrm{n}=0)\end{array}$ & $\begin{array}{l}\text { Subgroup A: lactate levels within } \\
\text { the normal range }(\mathrm{n}=2) \\
\text { Subgroup B: lactate levels above the } \\
\text { normal range }(>1.6 \mathrm{mmol} / \mathrm{l})(\mathrm{n}=2)\end{array}$ \\
\hline & $\begin{array}{l}\text { Presence of pressure ulcers on } \\
\text { admission to IC }\end{array}$ & $\begin{array}{l}\text { Subgroup A: lactate levels within } \\
\text { the normal range }(\mathrm{n}=28) \\
\text { Subgroup B: lactate levels above the } \\
\text { normal range }(>1.6 \mathrm{mmol} / \mathrm{l})(\mathrm{n}=7)\end{array}$ & $\begin{array}{l}\text { Subgroup A: lactate levels within } \\
\text { the normal range }(\mathrm{n}=11) \\
\text { Subgroup B: lactate levels above the } \\
\text { normal range }(>1.6 \mathrm{mmol} / \mathrm{l})(\mathrm{n}=24)\end{array}$ \\
\hline
\end{tabular}

Figure I Study flow.

This was a retrospective, non-randomised study. The study was approved by the Bioethical Commission at the Military Medical Chamber in Warsaw (No. KB - 186/21) and complies with the Declaration of Helsinki.

We analysed the patients' lactate levels, as measured by arterial blood gas analysis, and monitored their pressure ulcers using their medical records: the pressure ulcer monitoring chart, the Waterlow pressure ulcer risk assessment chart, history of present illness and medical history. In the present study we used the study by Yepes et al investigating the relationship between pressure ulcer development and length of stay in ICU. ${ }^{33}$

\section{Statistical Chapter}

The study group was compared with total Polish PU of the calculated incidence rate: 10.2 per 10,000 people. Statistical analysis was performed using the Statistica software. The $\chi^{2}$ test of independence was used to test research hypotheses and examine the significance of differences for one degree of freedom (df). A level of significance of $\mathrm{p}=0.05$ was used in the study. Sample size calculation (confidence level: 95\%, margin of error: 6\%, population proportion: 12\%, hospitalized population size: 327,000) resulted in 113 or more measurements in the study. Therefore, the study size seems to be suitable and adequate.

\section{Results}

The study was conducted among patients aged between 19 and 94 years. The mean age of the patients was 64.9 years, with similar mean ages for men (64.0) and women (66.5). The patients stayed in ICU for between 1 and 98 days, with the mean duration of stay of 11.5 days. The maximum length of stay in ICU was 98 days for male patients and 64 days for 
Descriptive statistics regarding the age and gender composition of the

study participants, the number of days the patients stayed in ICU

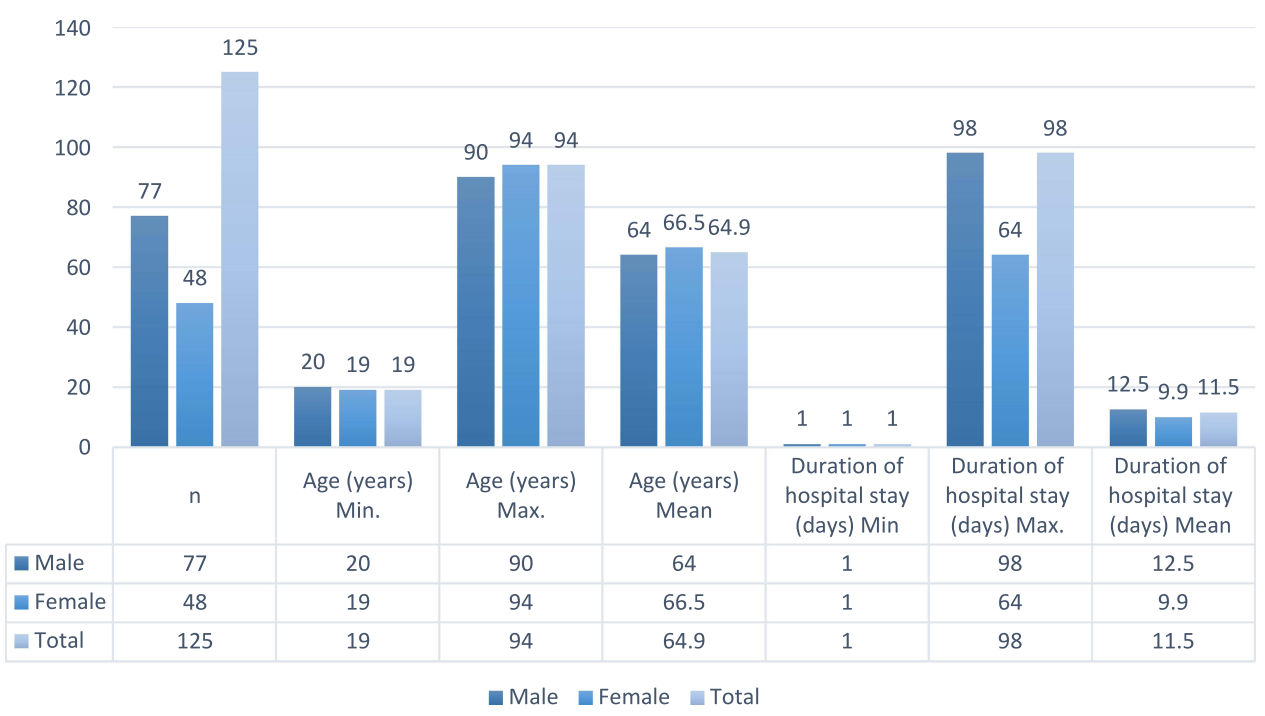

Figure 2 Descriptive statistics regarding the age and gender composition of the study participants, the number of days the patients stayed in ICU.

female patients. Lactate levels in the patients studied ranged between 0.2 and $30.0 \mathrm{mmol} / 1$. There were 35 deaths during the study period.

Figure 2 shows gender-specific statistics regarding the age of the patients and the number of days they stayed in ICU. Lactate levels were measured in each patient by arterial blood gas analysis at least several times during their stay in ICU. Based on the results of the arterial blood gas tests, the minimum and maximum lactate levels for each subgroup were determined. An analysis of results was carried out based on two separate groups: for minimum and maximum blood lactate levels. The results are shown in Tables 1 and 2. Our analysis for minimum lactate levels showed that only 10 patients (8\%) with no pressure ulcers had lactate levels above the reference range. The age range of the patients included in subgroup 1A (19-94 years) was similar to that of patients in subgroup 1B (20-87 years). Patients with no pressure ulcers and with low lactate levels stayed in ICU for between 1 and 64 days. There were 13 deaths in that group of patients. Our analysis showed that patients with lactate levels above the normal range and with no pressure ulcers stayed in ICU for between 1 and 7 days. Nine of those patients died. Subgroups 2A and 2B included patients who developed pressure ulcers while staying in ICU. In $11(8.8 \%)$ of those patients' lactate levels ranged between 0.2 and 1.5 and were considered to be within the reference range. The mean age of those patients was 68 years. The patients in the two subgroups stayed in ICU the longest, with the length of stay ranging from 4 to 98 days. Two of those patients died. All the patients who developed pressure ulcers during their stay in ICU had lactate levels within the normal range. Group 3A included patients with pressure ulcers on admission. Their length of stay in ICU ranged between 4 and 43 days and their lactate levels did not exceed 1.6. Five of those patients died. Six patients included in group 3B died and lactate levels in that group were above the reference range (1.7-12.9). The mean age of those patients was 64.3 years. The relationship between pressure ulcer development and blood lactate levels was tested using the maximum likelihood chi-square test. However, the test did not show a statistically significant relationship $(\mathrm{p}=0.1127)$. Our analysis for maximum lactate levels showed the following for group 1A, which included patients without pressure ulcers and with lactate levels within the normal range: age range of 19-94 years, duration of stay in ICU ranging from 1 to 26 days, 4 deaths; moreover, there were more men than women in that group. There were 19 deaths in group 1B, which included patients without pressure ulcers who had lactate levels above the normal range. Four patients $(3.2 \%)$ developed pressure ulcers during their stay in ICU. There was one death in that group of patients. The third group included 35 patients (28\%), of whom 11 had pressure ulcers on admission to ICU and had lactate levels within the normal range. Those patients stayed in ICU for between 4 and 20 days and were aged between 27 and 
Table I Characteristics of the Groups Studied Calculated for Minimum Lactate Levels

\begin{tabular}{|c|c|c|c|c|c|c|c|c|}
\hline \multicolumn{9}{|c|}{ Lactate Levels - Min. } \\
\hline \multirow{2}{*}{\multicolumn{2}{|c|}{ Variables }} & IA & IB & $2 A$ & 2B & 3A & 3B & Total Number of Study Participants \\
\hline & & $6955.2 \%$ & $108.0 \%$ & II $8.8 \%$ & $00.0 \%$ & $2822.4 \%$ & $75.6 \%$ & 125 \\
\hline \multicolumn{2}{|c|}{ Age range } & 19-94 & $20-87$ & $46-85$ & - & 27-90 & $58-78$ & 19-94 \\
\hline \multicolumn{2}{|c|}{ Age (mean $\pm S D)$} & $64.5 \pm 15.9$ & $60.4 \pm 21.9$ & $68.0 \pm 10.2$ & - & $66.6 \pm 17.5$ & $64.3 \pm 6.9$ & $64.9 \pm 15.9$ \\
\hline \multirow[t]{2}{*}{ Gender } & M & $3956.5 \%$ & $550.0 \%$ & $545.5 \%$ & $00.0 \%$ & $2382.1 \%$ & $571.4 \%$ & $571.4 \%$ \\
\hline & $\mathrm{F}$ & $3043.5 \%$ & $550.0 \%$ & $654.5 \%$ & $00.0 \%$ & $517.9 \%$ & $571.4 \%$ & $4838.4 \%$ \\
\hline \multicolumn{2}{|c|}{$\begin{array}{l}\text { Range of duration of stay } \\
\text { in ICU }\end{array}$} & $1-64$ & $\mathrm{I}-7$ & $4-98$ & - & $4-43$ & $1-17$ & I-98 \\
\hline \multicolumn{2}{|c|}{$\begin{array}{l}\text { Range of lactate levels } \\
{[\mathrm{mmol} / \mathrm{l}]}\end{array}$} & $0.2-1.5$ & $1.7-30.0$ & $0.2-1.5$ & - & $0.2-1.6$ & $1.7-12.9$ & $0.2-30.0$ \\
\hline \multicolumn{2}{|l|}{ Death } & 13 & 9 & 2 & 0 & 5 & 6 & 35 \\
\hline
\end{tabular}

Abbreviations: IA, absence of pressure ulcers + lactate levels within the normal range; IB, absence of pressure ulcers + lactate levels above the normal range (>I.6 mmol/ I); $2 \mathrm{~A}$, pressure ulcers acquired during ICU stay + lactate levels within the normal range; $2 \mathrm{~B}$, pressure ulcers acquired during ICU stay + lactate levels above the normal range $(>I .6 \mathrm{mmol} / \mathrm{l}) ; 3 \mathrm{~A}$, presence of pressure ulcers on admission to ICU + lactate levels within the normal range, $3 \mathrm{~B}$, presence of pressure ulcers on admission to ICU + lactate levels above the normal range $(>1.6 \mathrm{mmol} / \mathrm{l})$.

Table 2 Characteristics of the Groups Studied Calculated for Maximum Lactate Levels

\begin{tabular}{|c|c|c|c|c|c|c|c|c|}
\hline \multicolumn{9}{|c|}{ Lactate Levels - Max. } \\
\hline \multirow{2}{*}{\multicolumn{2}{|c|}{ Variables }} & IA & IB & 2A & 2B & 3A & 3B & Total Number of Study Participants \\
\hline & & $3427.2 \%$ & $5241.6 \%$ & $21.6 \%$ & $21.6 \%$ & II $8.8 \%$ & $2419.2 \%$ & 125 \\
\hline \multicolumn{2}{|c|}{ Age range } & 19-94 & $20-90$ & $70-87$ & $46-80$ & $27-90$ & $52-89$ & 19-94 \\
\hline \multicolumn{2}{|c|}{ Age (mean $\pm S D)$} & $61.2 \pm 16.6$ & $66.1 \pm 15.4$ & $78.5 \pm 12.0$ & $63.0 \pm 24.0$ & $58.5 \pm 22.4$ & $69.6 \pm 10.7$ & $64.9 \pm 15.9$ \\
\hline \multirow[t]{2}{*}{ Gender } & M & $2264.7 \%$ & $2548.1 \%$ & $00.0 \%$ & $2100 \%$ & $981.8 \%$ & $1979.2 \%$ & $7761.6 \%$ \\
\hline & $\mathrm{F}$ & $1235.3 \%$ & $2751.9 \%$ & $2100 \%$ & $00.0 \%$ & $218.2 \%$ & $520.8 \%$ & $4838.4 \%$ \\
\hline \multicolumn{2}{|c|}{$\begin{array}{l}\text { Range of duration of } \\
\text { stay in ICU }\end{array}$} & $\mathrm{I}-26$ & $1-98$ & $5-13$ & $4-5$ & $4-20$ & $1-43$ & $1-98$ \\
\hline \multicolumn{2}{|c|}{$\begin{array}{l}\text { Range of lactate levels } \\
{[\mathrm{mmol} / \mathrm{l}]}\end{array}$} & $0.6-1.6$ & I.7-30.0 & $0.9-1.6$ & $2.3-4.9$ & $0.7-1.6$ & I.7-23.0 & $0.2-30.0$ \\
\hline \multicolumn{2}{|l|}{ Death } & 4 & 19 & I & 0 & 0 & 11 & 35 \\
\hline
\end{tabular}

Abbreviations: IA, absence of pressure ulcers + lactate levels within the normal range; IB, absence of pressure ulcers + lactate levels above the normal range (>I.6 mmol/ I); $2 \mathrm{~A}$, pressure ulcers acquired during ICU stay + lactate levels within the normal range; $2 \mathrm{~B}$, pressure ulcers acquired during ICU stay + lactate levels above the normal range $(>1.6 \mathrm{mmol} / \mathrm{I}) ; 3 \mathrm{~A}$, presence of pressure ulcers on admission to ICU + lactate levels within the normal range; $3 \mathrm{~B}$, presence of pressure ulcers on admission to ICU + lactate levels above the normal range $(>1.6 \mathrm{mmol} / \mathrm{l})$.

90 years. There were 11 deaths in group 3B, which included patients with high lactate levels (1.7-23.0) and with pressure ulcers on admission. The patients included in that group were aged between 52 and 89 years and stayed in ICU for between 1 and 43 days. The analysis was carried out using the maximum likelihood chi-square test to determine the relationship between lactate levels, as measured by arterial blood gas analysis, and the presence of pressure ulcers. The test did not show a statistically significant relationship $(\mathrm{p}=0.6148)$. Our study showed that the incidence of pressure ulcers in the intensive care unit patients studied is $8.8 \%$, which is not statistically different to the incidence rates reported in the literature. According to the 2020 hospitalization report, about 327,000 patients are 
hospitalized in Poland. The median prevalence of PU in hospitalized patients is approximately $12 \%{ }^{4}$ which means every year 39,240 people are at risk of developing a PU in Poland. The incidence rate measured for Poles is 10.2 per 10,000 people. We found that there was no difference in the incidence of pressure ulcers between the female and male patients studied. An analysis of the findings from the study did not show a clear association between blood lactate levels and the development of pressure ulcers due to low expected values. We suggest that further research on a larger population is required.

\section{Discussion}

Elevated lactate levels can be observed in all conditions accompanied by significant hypoxia, such as shock, thrombosis, anaemia and acute respiratory failure, either of pulmonary or cardiovascular origin. They can be used in the diagnostic process as a sensitive prognostic factor with regard to the outcomes and treatment of patients. Sustained acidosis constitutes a pathological mechanism responsible for systemic inflammation, which leads to multi-organ failure. Metabolic acidosis also results in intensification of catabolic processes and systemic weakness caused by reduction in lean mass. Acidosis inhibits the synthesis of albumins and plays an indirect role in the development of heart failure as it inhibits the activities of $\mathrm{Na}^{+} / \mathrm{K}^{+}$-ATPase in heart muscle cells and red blood cells. ${ }^{34-36}$ Lactate clearance in the body is dependent on the rate of oxidation in the relevant organs. ${ }^{37}$ When liver perfusion decreases by $70 \%$ and renal perfusion decreases by $90 \%$, the organs not only stop removing lactate but they also start to produce it themselves. ${ }^{38,39}$ Numerous studies have shown that there is a link between lactate levels in the immediate postoperative period after cardiac surgery and both serious complications and postoperative mortality. ${ }^{30,40-47}$ It has also been shown that the measurement of blood lactate levels is useful in the diagnosis and evaluation of hypoxia and lactic acidosis in patients in shock or with heart failure. ${ }^{48,49}$ There are studies in the literature that investigated the significance of intraoperative changes in lactate levels. Their findings showed that such changes are associated with worse short-term outcomes in patients after cardiac surgery with cardiopulmonary bypass. ${ }^{50}$ There are also studies that have found that there is a correlation between an increase in lactate levels in sweat and application of loads. ${ }^{51}$ Those studies suggest that more research is needed into this association as lactate levels have the potential to act as a biomarker for the development of pressure ulcers. ${ }^{51-53}$ In light of the known mechanism underlying pressure ulcer formation, involving ie reduced tissue perfusion, and the fact that lactate levels increase when the supply of oxygen is reduced, the significance of elevated lactate levels as a potential biomarker for pressure ulcer development should be further investigated. The incidence of pressure ulcers in patients admitted to intensive care units ranges between 3.3\% and 52.9\%. ${ }^{54}$ A study by Sayar et al shows a PU prevalence of $14.3 \%$ in Intensive Care Unit patients at Waterlow's risk group. This study indicates the involvement of long hospitalization and inactivity in the development of PU. ${ }^{55}$ A systematic review and meta-analysis of 35 studies by Borojeny et al show that the worldwide prevalence of pressure ulcers in hospitalized patients is $12 \%,{ }^{3}$ however, studies in the United States estimate a prevalence from 8 to $40 \%{ }^{56}$ The incidence of PU at the Department of Anesthesiology of the 4th Military Teaching Hospital in Wroclaw shown in this study (8.8\%) does not differ from the results presented in the literature and is similar to the results of the European population. Despite the lack of proof of an association between elevated lactate levels and the occurrence of PU due to a too-small study group, it is suggested that this cause should be taken into consideration. At this point, it is not possible to compare the results with available data as no studies were found on this topic. The present study did not confirm an association between pressure ulcer development and lactate levels measured by arterial blood gas analysis. Although our study group was sufficiently large, the expected values were low due to the division of the groups studied into small subgroups. Therefore, we suggest that the findings from the study should be interpreted with caution. We would encourage that further research covering a much longer time period and enabling the collection of data relating to more than 1000 patients be conducted into the association between lactate levels and pressure ulcer formation in order to confirm or refute the hypothesis in question. Medical publications have reported findings that confirm an association between reduced albumin levels and increased blood lactate levels in patients after surgery. There are also many studies investigating the prognostic significance of lactate levels in the perioperative period or the behaviour of serum lactate levels in patients undergoing mechanical ventilation. ${ }^{29,52,57}$ However, we found no studies in which lactate levels were identified as a risk or prognostic factor for pressure ulcer formation in patients. Our present study was motivated by the importance of pressure ulcers and the wish to identify prognostic factors for pressure 
ulcer development as well as the lack of scientific data that would verify the relationship between pressure ulcer formation and lactate levels. Even though our study did not confirm the association in question, we believe that the issue concerned should be investigated further. We suggest that further research into the issue should take into account the fact that rapid therapeutic interventions performed in patients can mask the actual behaviour of arterial blood lactate levels in patients with pressure ulcers, which prevents the association between lactate levels and pressure ulcer formation from being fully understood. Such research could have an impact on many aspects of medical care, including care of the physical and mental health of patients, length of hospital stay, assessment of quality of care, treatment costs and prognosis for the life and health of the patient.

\section{Study Limitations}

Considering the low expected values due to the small number of patients included in each subgroup, the findings from the study should be treated with caution. Given the importance of the issue of pressure ulcers in patients, a larger population study covering a longer period of time seems warranted.

\section{Conclusions}

The present study did not show a direct correlation between the patients' arterial blood lactate levels and the incidence of pressure ulcers. The incidence of pressure ulcers in ICU patients is not different from the incidence rates reported in the literature. Considering the low expected values due to the small number of patients in each subgroup, the findings should be treated with caution. Given the importance of pressure ulcers, a larger population study covering a longer period of time seems warranted.

\section{Data Sharing Statement}

The datasets analysed during the present study are included in this article.

\section{Ethics Approval and Consent to Participate}

The study was approved by the Bioethical Commission at the Military Medical Chamber in Warsaw (No. KB - 186/21). The study complies with the Declaration of Helsinki.

\section{Consent for Publication}

All the patients gave written formal consent to participate.

\section{Author Contributions}

AW - Acquisition and analysis of data for the work. IS - Drafting the work and revising it critically for important intellectual content. AD - Acquisition and analysis of data for the work. WM - Writing the manuscript. MC - Translation and final approval of the version to be published. All authors made a significant contribution to the work reported, whether that is in the conception, study design, execution, acquisition of data, analysis and interpretation, or in all these areas; took part in drafting, revising or critically reviewing the article; gave final approval of the version to be published; have agreed on the journal to which the article has been submitted; and agree to be accountable for all aspects of the work.

\section{Funding}

The authors received financial support for this research from Wroclaw Medical University: SUBZ.E250.22.095.

\section{Disclosure}

The authors declare that they have no competing interests. 


\section{References}

1. Lyder CH, Preston J, Grady JN, et al. Quality of care for hospitalized medicare patients at risk for pressure ulcers. Arch Intern Med. 2001;161 (12):1549-1554. doi:10.1001/archinte.161.12.1549

2. Allman RM, Goode PS, Burst N, Bartolucci AA, Thomas DR. Pressure ulcers, hospital complications, and disease severity: impact on hospital costs and length of stay. Adv Wound Care. 1999;12(1):22-30.

3. Borojeny LA, Albatineh AN, Hasanpour Dehkordi A, Ghanei Gheshlagh R. The incidence of pressure ulcers and its associations in different wards of the hospital: a systematic review and meta-analysis. Int J Prev Med. 2020;11:171. doi:10.4103/ijpvm.IJPVM_182_19

4. Kaltenhaler E, Whitfield MD, Walters SJ, Akehurst RL, Paisley S. UK, USA and Canada: how do their pressure ulcer prevalence and incidence data compare? J Wound Care. 2001;10:530-535.

5. Phillips L, Buttery J. Exploring pressure ulcer prevalence and preventative care. Nurs Times. 2009;105:34-36.

6. VanGilder C, Amlung S, Harrison P, Meyer S. Results of the 2008-2009 international pressure ulcer prevalence survey and a 3-year, acute care, unit-specific analysis. Ostomy Wound Manage. 2009;55:39-45.

7. Vanderwee K, Clark M, Dealey C, Gunningberg L, Defloor T. Pressure ulcer prevalence in Europe: a pilot study. J Eval Clin Pract. 2007;13:227-235. doi:10.1111/j.1365-2753.2006.00684.x

8. Kandilov AM, Coomer NM, Dalton K. The impact of hospital-acquired conditions on medicare program payments. Medicare Medicaid Res Rev. 2014;4:mmrr2014-004-04-a01. doi:10.5600/mmrr.004.04.a01

9. Coyer F, Miles S, Gosley S, et al. Pressure injury prevalence in intensive care versus non-intensive care patients: a state-wide comparison. Aust Crit Care. 2017;30:244-250. doi:10.1016/j.aucc.2016.12.003

10. Pachá H, Faria J, Oliveira K, Beccaria L. Pressure ulcer in intensive care units: a case-control study. Rev Bras Enferm. 2018;71:3027-3034. doi:10.1590/0034-7167-2017-0950

11. Yarkony GM. Pressure ulcers: a review. Arch Phys Med Rehabil. 1994;75(8):908-917. doi:10.1016/0003-9993(94)90117-1

12. Dantas ALM, Ferreira PC, Valença CN, Diniz KD, Nunes JP, Germano RM. Complicações das úlceras por pressão para o paciente grave: estudo descritivo-exploratório. [Complications of pressure ulcers in severely ill patients: a descriptive-exploratory study]. $O$ Braz $J$ Nurs. 2013;12:319-329.

13. Livesley NJ, Chow AW. Infected pressure ulcers in elderly individuals. Clin Infect Dis. 2002;35:1390-1396. doi:10.1086/344059

14. Jiang H, Liang Y, Liu X, et al. The risk factors-based nursing case management could effectively reduce the incidence of pressure sores in hospitalized patients. Iran J Public Health. 2021;50:566-572. doi:10.18502/ijph.v50i3.5601

15. Banks V. Nutrition and pressure area management. $J$ Wound Care. 1998;7:318-319.

16. Casey G. The importance of nutrition in wound healing. Nurs Stand. 1998;13:51-52. doi:10.7748/ns 1998.10.13.3.51.c2534

17. Prior J. The pressure is on: midwives and decubitus ulcers. RCM Midwives J. 2002;5:196-200.

18. Gallagher SM. Morbid obesity: a chronic disease with an impact on wound and related problems. Ostomy Wound Manag. 1997;43:18-24, 26-27.

19. Nassaji M, Askari Z, Ghorbani R. Cigarette smoking and risk of pressure ulcer in adult intensive care unit patients. Int $J$ Nurs Pract. 2014;20:418-423. doi:10.1111/ijn.12141

20. Ülker E, Yapucu Ü. A prospective, descriptive study of risk factors related to pressure ulcer development among patients in intensive care units. Ostomy Wound Manag. 2013;59:22-27.

21. Shahin ES, Dassen T, Halfens RJ. Pressure ulcer prevalence in intensive care patients: a cross-sectional study. J Eval Clin Pract. 2008;14:563-568. doi:10.1111/j.1365-2753.2007.00918.x

22. Frankel H, Sperry J, Kaplan L. Risk factors for pressure ulcer development in a best practice surgical intensive care unit. Am Surg. 2007;73:1215-1217. doi:10.1177/000313480707301203

23. Oliveira KF, Nascimento KG, Nicolussi AC, Chavaglia SRR, Araújo CA, Barbosa MH. Support surfaces in the prevention of pressure ulcers in surgical patients: an integrative review. Int J Nurs Pract. 2017;23:e12553. doi:10.1111/ijn.12553

24. Scarlatti KC, Michel JLM, Gamba MA, Gutiérrez MGRD.Pressure ulcers in surgery patients: incidence and associated factors. Rev Esc Enferm USP.2011;45:1372-1379. doi:10.1590/S0080-62342011000600014

25. Spruce L. Back to basics: preventing perioperative pressure injuries. AORN J. 2017;105:92-99. doi:10.1016/j.aorn.2016.10.018

26. O'Brien DD, Shanks AM, Talsma A, Brenner PS, Ramachandran SK. Intraoperative risk factors associated with postoperative pressure ulcers in critically ill patients: a retrospective observational study. Crit Care Med. 2014;42:40-47. doi:10.1097/CCM.0b013e318298a849

27. Nijs N, Toppets A, Defloor T, Bernaerts K, Milisen K, Van Den Berghe G. Incidence and risk factors for pressure ulcers in the intensive care unit. J Clin Nurs. 2009;18:1258-1266. doi:10.1111/j.1365-2702.2008.02554.x

28. Serrano ML, Mendez MG, Cebollero FC, Rodriguez JL. Risk factors for pressure ulcer development in intensive care units: a systematic review. Med Intensiva. 2017;41:339-346. doi:10.1016/j.medin.2016.09.003

29. Kim JM, Lee H, Ha T, Na S. Perioperative factors associated with pressure ulcer development after major surgery. Korean $J$ Anesthesiol. 2018;71:48. doi:10.4097/kjae.2018.71.1.48

30. Okorie ON, Dellinger P. Lactate: biomarker and potential therapeutic target. Crit Care Clin. 2011;27:299-326. doi:10.1016/j.ccc.2010.12.013

31. Kjelland CB, Djogovic D. The role of serum lactate in the acute care setting. J Intensive Care Med. 2010;25:286-300. doi:10.1177/ 0885066610371191

32. Haidl F, Brabrand M, Henriksen DP, Lassen AT. Lactate is associated with increased 10-day mortality in acute medical patients: a hospital based cohort study. Eur J Emerg Med. 2015;22:282-284. doi:10.1097/MEJ.0000000000000210

33. Yepes D, Molina F, León W, Pérez E. Incidence and risk factors associated with the presence of pressure ulcers in critically ill patients. Med Intensiva. 2009;33:276-281. doi:10.1016/S0210-5691(09)72195-3

34. Kraut JA, Madias NE. Consequences and therapy of the metabolic acidosis of chronic kidney disease. Pediatr Nephrol. 2011;26:19-28. doi:10.1007/s00467-010-1564-4

35. Rozier MD, Zata VJ, Ellsworth ML. Lactate interferes with ATP release from red blood cells. Am J Physiol Heart Circ. 2007;292:H3038-H3042. doi:10.1152/ajpheart.01238.2006

36. Dobre M, Yang W, Chen J, et al. Association of serum bicarbonate with risk of renal and cardiovascular outcomes in CKD: a report from the Chronic Renal Insufficiency Cohort (CRIC) study. Am J Kidney Dis. 2013;62:670-678. doi:10.1053/j.ajkd.2013.01.017 
37. Boldt J, Piper S, Murray P, Lehmann A. Severe lactic acidosis after cardiac surgery: sign of perfusion deficits? J Cardiothorac Vasc Anesth. 1999;13:220-224. doi:10.1016/S1053-0770(99)90093-9

38. Packer RA, Cohn LA, Wohlstadter DR, et al. D-Lactic acidosis secondary to exocrine pancreatic insufficiency in a cat. $J$ Vet Intern Med. 2005;19:106-110. doi:10.1111/j.1939-1676.2005.tb02667.x

39. Madias NE. Lactic acidosis. Kidney Int. 1986;29:752-774. doi:10.1038/ki.1986.62

40. Mustafa I, Roth H, Hanafiah A, et al. Effect of cardiopulmonary bypass on lactate metabolism. Intensive Care Med. 2003;29:1279-1285. doi:10.1007/s00134-003-1860-6

41. Luft FC. Lactic acidosis update for critical care clinicians. J Am Soc Nephrol. 2001;12:15-19. doi:10.1681/ASN.V12suppl 1s15

42. McNelis J, Marini CP, Jurkiewicz A, et al. Prolonged lactate clearance is associated with increased mortality in the surgical intensive care unit. Am J Surg. 2001;182:481-485. doi:10.1016/S0002-9610(01)00755-3

43. Attanà $\mathrm{P}$, Lazzeri $\mathrm{C}$, Picariello $\mathrm{C}$, Dini CS, Gensini GF, Valente S. Lactate and lactate clearance in acute cardiac care patients. Eur Heart J Acute Cardiovasc Care. 2012;1:115-121. doi:10.1177/2048872612451168

44. Maillet JM, Le Besnerais P, Cantoni M, et al. Frequency, risk factors, and outcome of hyperlactatemia after cardiac surgery. Chest. 2003;123:1361-1366. doi:10.1378/chest.123.5.1361

45. Kogan A, Preisman S, Bar A, et al. The impact of hyperlactatemia on postoperative outcome after adult cardiac surgery. $J$ Anesth. 2012;26:174-178. doi:10.1007/s00540-011-1287-0

46. Zante B, Kubik M, Reichenspurner H. Lactate level as a prognostic factor of mortality in patients after cardiac surgery. Thorac Cardiovasc Surg. 2010;58:43. doi:10.1055/s-0029-1246813

47. Mirmohammad-Sadeghi M, Etesampour A, Gharipour M, et al. Relationship between serum lactate levels and morbidity outcomes in cardiovascular patients after CABG. J Surg Pak Int. 2008;13:88-91.

48. O'Connor E, Fraser JF. The interpretation of perioperative lactate abnormalities in patients undergoing cardiac surgery. Anaesth Intensive Care. 2012;40:598-603. doi:10.1177/0310057X1204000404

49. Ezekowitz JA, McAlister FA, Armstrong PW. Anemia is common in heart failure and is associated with poor outcomes: insight from a cohort of 12 065 patients with new-onset heart failure. Circulation. 2003;107:223-225. doi:10.1161/01.CIR.0000052622.51963.FC

50. Duval B, Besnard T, Mion S, et al. Intraoperative changes in blood lactate levels are associated with worse short-term outcomes after cardiac surgery with cardiopulmonary bypass. Perfusion. 2019;34:640-650. doi:10.1177/0267659119855857

51. Soetens JFJ, Worsley PR, Herniman JM, Langley GJ, Bader DL, Oomens CW. The expression of anaerobic metabolites in sweat and sebum from human skin subjected to intermittent and continuous mechanical loading. J Tissue Viability. 2019;28:186-193. doi:10.1016/j.jtv.2019.10.001

52. Hatanaka N, Yamamoto Y, Ichihara K, et al. A new predictive indicator for development of pressure ulcers in bedridden patients based on common laboratory tests results. J Clin Pathol. 2008;61:514-518. doi:10.1136/jcp.2007.050195

53. Ferguson-Pell M, Hagisawa S. Biochemical changes in sweat following prolonged ischemia. J Rehabil Res Dev. 1988;25:57-62.

54. Costa ACO, Pinho CPS, Dos Santos ADA, Nascimento ACS. Pressure ulcer: incidence and demographic, clinical and nutrition factors: associated in intensive care unit patients. Nutr Hosp. 2015;32:2242-2252.

55. Sayar S, Turgut S, Doğan H, et al. Incidence of pressure ulcers in intensive care unit patients at risk according to the Waterlow scale and factors influencing the development of pressure ulcers. J Clin Nurs. 2009;18:765-774. doi:10.1111/j.1365-2702.2008.02598.x

56. Kaitani T, Tokunaga K, Matsui N, Sanada H. Risk factors related to the development of pressure ulcers in the critical care setting. J Clin Nurs. 2010;19:414-421. doi:10.1111/j.1365-2702.2009.03047.x

57. Deng XJ, Zou Y, Wu J, Liang Y, Gu SY. The effect of blood lactate and NT-proBNP predict the survival in patients with invasive mechanical ventilation. Ann Transl Med. 2020;8:458. doi:10.21037/atm.2020.03.140

Journal of Inflammation Research

Dovepress

\section{Publish your work in this journal}

The Journal of Inflammation Research is an international, peer-reviewed open-access journal that welcomes laboratory and clinical findings on the molecular basis, cell biology and pharmacology of inflammation including original research, reviews, symposium reports, hypothesis formation and commentaries on: acute/chronic inflammation; mediators of inflammation; cellular processes; molecular mechanisms; pharmacology and novel anti-inflammatory drugs; clinical conditions involving inflammation. The manuscript management system is completely online and includes a very quick and fair peer-review system. Visit http://www.dovepress.com/testimonials.php to read real quotes from published authors.

Submit your manuscript here: https://www.dovepress.com/journal-of-inflammation-research-journal 